
Not for reproduction, distribution or commercial use.

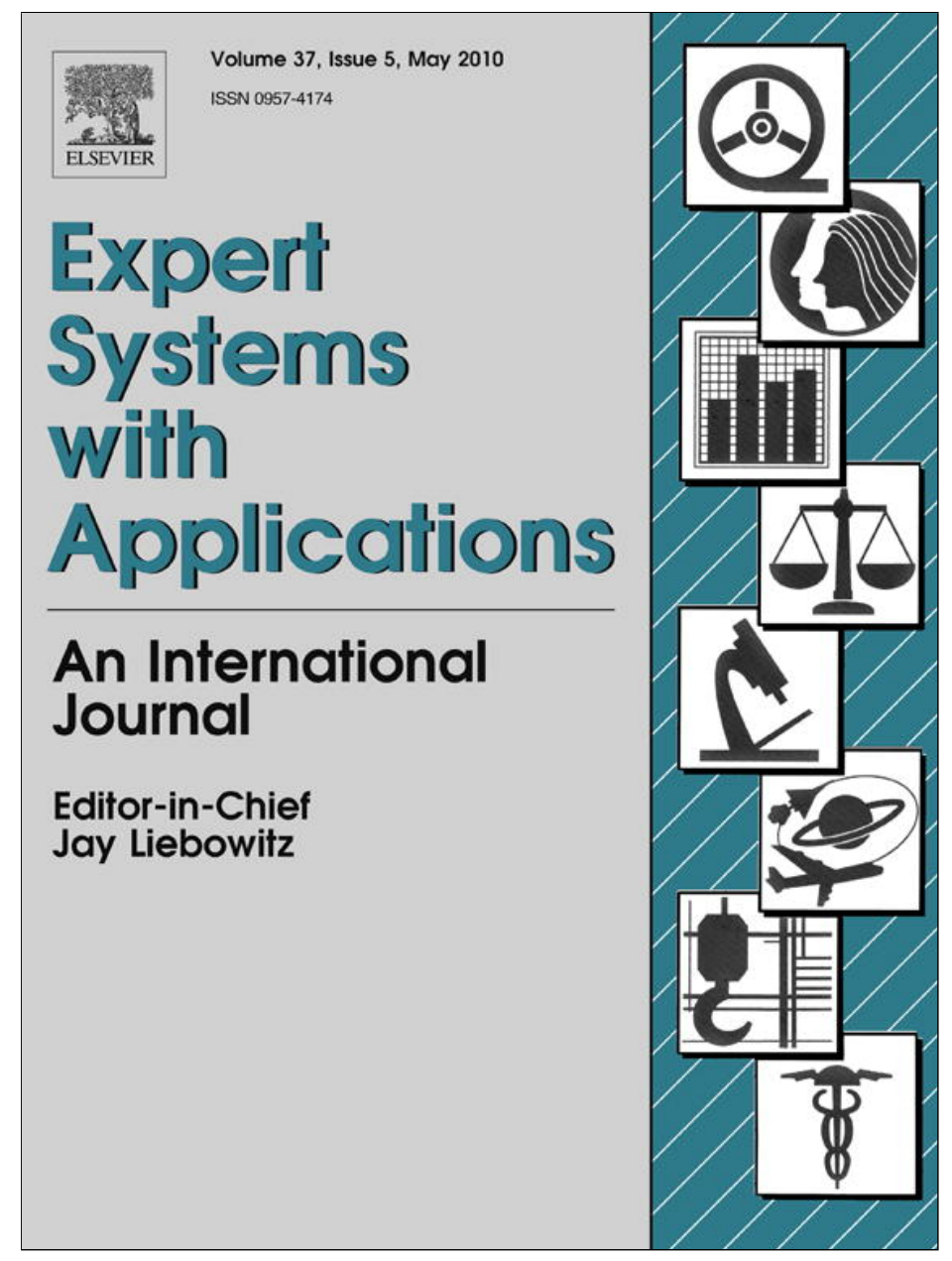

This article appeared in a journal published by Elsevier. The attached copy is furnished to the author for internal non-commercial research and education use, including for instruction at the authors institution and sharing with colleagues.

Other uses, including reproduction and distribution, or selling or licensing copies, or posting to personal, institutional or third party websites are prohibited.

In most cases authors are permitted to post their version of the article (e.g. in Word or Tex form) to their personal website or institutional repository. Authors requiring further information regarding Elsevier's archiving and manuscript policies are encouraged to visit: 


\title{
The THOMAS architecture in Home Care scenarios: A case study
}

\author{
Javier Bajo $^{\mathrm{a}, *}$, Juan A. Fraile ${ }^{\mathrm{a}}$, Belén Pérez-Lancho ${ }^{\mathrm{b}}$, Juan M. Corchado ${ }^{\mathrm{b}}$ \\ ${ }^{a}$ Universidad Pontificia de Salamanca, Compañía 5, 37002 Salamanca, Spain \\ ${ }^{\mathrm{b}}$ Departamento Informática y Automática Universidad de Salamanca, Plaza de la Merced s/n, 37008 Salamanca, Spain
}

\section{A R T I C L E I N F O}

\section{Keywords:}

Dependent environments

Multi-agent systems

Home Care

Virtual organizations

\begin{abstract}
A B S T R A C T
Today, the need for architectures and computational models for large scale open multi-agent systems is considered a key issue for the success of agent technology in real world scenarios. The main goal of this paper is to describe a case study in Home Care scenarios applying an abstract architecture and a computational model for large scale open multi-agent systems based on a service-oriented approach. The architecture used is THOMAS, which specifically addresses the design of Home Care systems. This paper presents services examples for the management of a dependent home environment, and demonstrates the new features of the proposal.
\end{abstract}

(c) 2009 Elsevier Ltd. All rights reserved.

\section{Introduction}

Home Care is one of the objectives of pervasive computing, and dependent people require new solutions that can take advantage of technological advances which provide novel and fundamental services (Angulo \& Tellez, 2004). The vision of pervasive computing is to improve the quality, access, equity and continuity of health care (Angulo \& Tellez, 2004). In this sense, intelligent environments can improve health care services and can have a high social impact, especially in Home Care services for chronically dependent patients (Augusto \& McCullagh, 2007). Because Home Care requires effective communication as well as distributed problem solving (Augusto \& McCullagh, 2007), multi-agent systems can facilitate the development of pervasive Home Care environments. Moreover, agent-oriented methodologies provide mechanisms for modelling distributed, inter-operable and secure systems by taking social and organizational considerations into account. Agents are autonomous software entities (Camarinha-Matos \& Afsarmanesh, 2004) able to interact with their surroundings. They are highly capable of adapting to changes, and can allow for integration with multiple devices, sensors and humans.

The continuous growth of the dependent people sector has dramatically increased the need for new Home Care solutions (Anastasopoulos, Niebuhr, Bartelt, Koch, \& Rausch, 2005; Corchado \& Laza, 2003). Furthermore, commitments to meet the needs of this sector suggest that the current systems are in need of modernization. Multi-agent systems (Want, Pering, Borriello, \& Farkas, 2002) and intelligent device-based architectures have been recently explored as supervisor systems in health care scenarios

\footnotetext{
* Corresponding author. Tel.: +34 639771985; fax: +34 923277101.

E-mail addresses: jbajope@upsa.es (J. Bajo), jafraileni@upsa.es (J.A. Fraile), lancho@usal.es (B. Pérez-Lancho), corchado@usal.es (J.M. Corchado).
}

(Angulo \& Tellez, 2004) for elderly people and for Alzheimer patients (Corchado \& Laza, 2003). These systems are capable of providing constant care in the daily life of dependent patients (Carrascosa, Bajo, Julian, Corchado, \& Botti, 2008), predicting potentially dangerous situations, and facilitating a cognitive and physical support for the dependent patient (Augusto \& McCullagh, 2007). Taking these solutions into account, it is possible to assume that multi-agent systems can further facilitate the design and development of pervasive environments (Corchado, Bajo, de Paz, \& Tapia, 2008) and improve the services currently available by incorporating new functionalities. Multi-agent systems add a high level of abstraction with respect to the traditional distributed computing solutions. They also facilitate the analysis and design of the problem in terms of artificial intelligence systems. This allows a greater flexibility for incorporating human behaviours into the agent's structure. Multi-agent system technology makes it possible to cover a broad area of problems. Typical problems are systems in which there are several entities (Requesters) which may require one or more elements or services from other different entities (Bidders). In the area of Home Care, for example, Requesters would be patients and Bidders would be companies which provide services, such as identification, localization, home automation services, or warnings and alerts. Obviously, the development of these types of systems is complex and, therefore, it is necessary to analyze the intrinsic characteristics of these typical application environments in detail.

The aim of this research project is to present a case study applying the THOMAS (MeTHods, Techniques and Tools for Open MultiAgent Systems) multi-agent architecture. THOMAS has been used to develop a case study for supervising and monitoring dependent patients at home. This multi-agent system offers a series of functionalities including an automatic reasoning and planning mechanism for scheduling the medical staff working day, an alert system, 
a location and tracking system, and an identification system. The medical staff has been provided with PDAs and mobile phones, as well as with Java Card tags, and the home environments have been equipped with presence detection sensors, access control mechanisms, door opening devices and video cameras. The multi-agent system monitors the daily routine of the patient and detects dangerous situations. If any anomalous situation is detected, the alert system is used to obtain medical assistance.

The remainder of this paper is structured as follows: Section 2 provides an analysis of related studies; Section 3 presents the proposed architecture model as well as a description of the services offered by each one of the modules that make up the reference model; Section 4 shows an example of an implementation, highlighting the new possibilities provided by this type of architecture, and presents a specific approach for Home Care management; finally, some conclusions of this study are shown in Section 5.

\section{Related works}

Dependence is a permanent situation in which a person needs important assistance from others in order to perform basic daily life activities such as essential mobility, object and people recognition, and domestic tasks (Costa-Font \& Patxot, 2005). There is an ever growing need to supply constant care and support to the disabled and elderly, and the drive to find more effective ways of providing such care has become a major challenge for the scientific community (Nealon \& Moreno, 2003). The importance of developing new and more reliable ways of providing care and support for the elderly is underscored by this situation, and the creation of secure, unobtrusive and adaptable environments for monitoring and optimizing health care will become vital. Some authors (Nealon \& Moreno, 2003) consider that tomorrow's health care institutions will be equipped with intelligent systems capable of interacting with humans. The intelligent systems aim to support patients in all aspects of daily life (Cesta, Bahadori, Cortellesa, Grisetti, \& Giuliani, 2003), predicting potential hazardous situations and delivering physical and cognitive support (Bahadori et al., 2003).

Home Care systems aim to improve quality of life, offering more efficient and easy ways to use services and communication tools to interact with other people, systems and environments. Among the general population, those most likely to benefit from the development of these systems are the elderly and dependent persons (i.e., those suffering from degenerative diseases, dementia or loss of cognitive ability (Costa-Font \& Patxot, 2005)), whose daily lives, with particular regard to health care, will be most enhanced (Corchado et al., 2008; Van Woerden, 2006).

Agents and multi-agent systems in dependency environments are becoming a reality, especially in health care. Most agent-based applications are related to the use of this technology in the monitoring of patients, treatment supervision and data mining. Lanzola, Gatti, Falasconi, and Stefanelli (1999) present a methodology that facilitates the development of inter-operable intelligent software agents for medical applications, and propose a generic computational model for implementing them. The model may be specialized in order to support all the different information and knowledge-related requirements of a hospital information system. Meunier (1999) proposes the use of virtual machines to support mobile software agents by using a functional programming paradigm. This virtual machine provides the application developer with a rich and robust platform upon which to develop distributed mobile agent applications, specifically when targeting distributed medical information and distributed image processing. While an interesting proposal, it is not viable due to the security reasons that affect mobile agents, and there is no defined alternative for locating patients or generating planning strategies. There are also agent-based systems that help patients get the best possible treatment, and that remind the patient about follow-up tests (Miksch, Cheng, \& Hayes-Roth, 1997). They assist the patient in managing continuing ambulatory conditions (chronic problems). They also provide health-related information by allowing the patient to interact with the on-line health care information network. Decker \& Li propose (Decker \& $\mathrm{Li}, 1998$ ) a system to increase hospital efficiency by using global planning and scheduling techniques. They propose a multi-agent solution that uses the generalized partial global planning approach which preserves the existing human organization and authority structures, while providing better system-level performance (increased hospital unit throughput and decreased impatient length of stay time). To do this, they use resource constraint scheduling to extend the proposed planning method with a coordination mechanism that handles mutually exclusive resource relationships. Other applications focus on home scenarios to provide assistance to elderly and dependent persons. RoboCare presents a multi-agent approach that covers several research areas, such as intelligent agents, visualization tools, robotics, and data analysis techniques to support people with their daily life activities (Pecora \& Cesta, 2007). TeleCARE is another application that makes use of mobile agents and a generic platform in order to provide remote services and automate an entire home scenario for elderly people (Camarinha-Matos \& Afsarmanesh, 2004). Although these applications expand the possibilities and stimulate research efforts to enhance the assistance and health care provided to elderly and dependent persons, none of them integrate intelligent agents, distributed and dynamic applications and services approach into their model.

In multi-agent systems (MAS) one of the most important goals is to build systems capable of autonomous and flexible decision-making. Moreover, these systems must cooperate with others within a "society". Due to the technological advances of recent years, the term "society", in which the multi-agent system participates, needs to meet several requirements such as: distribution, constant evolution, flexibility to allow members to enter or exit the society, appropriate management of the organizational structure that defines the society, multi-device agent execution including devices with limited resources, and so on. All of these requirements define a set of features that can be addressed through an open system paradigm and virtual organizations. Despite the large number of agent platforms in existence, the majority are lacking in the management of virtual organizations for dynamic, open and large-scale environments. For example, the most well-known agent platforms (like $J A D E$ ) (Argente et al., 2007) offer basic functionalities to agents, such as AMS and DF services; but designers must implement nearly all of the organizational features by themselves, namely organization representation, control mechanisms, organization descriptions, AMS and DF extensions, communication layer, monitoring, organization modelling support and organizational API.

The state-of-the-art in this field shows research interest in the integration of mobile agents and services, where agents are complex entities that can handle the problem of service discovery and composition in dynamic and changing open environments. Agents are not organized into plain societies, but into structured organizations that enclose the real world with the society representation and ease the development of open and heterogeneous systems. Current agent platforms must integrate these concepts to allow designers to employ higher abstractions when modelling and implementing these complex systems. All of these concerns can be found in the THOMAS architecture.

\section{THOMAS architecture model}

THOMAS architecture basically consists of a set of modular services. Though THOMAS feeds initially on the FIPA architecture, it 
expands its capabilities to deal with organizations and to boost its services abilities. In this way, a new module in charge of managing organizations is introduced into the architecture, along with a redefinition of the FIPA Directory Facilitator that is able to deal with services in a more elaborate way, following Service Oriented Architectures guidelines. As previously stated, services are very important in this architecture. In fact, agents have access to the THOMAS infrastructure through a range of services included in different modules or components. The main components of THOMAS are shown in Fig. 1.

- Service Facilitator (SF): this component offers simple and complex services to the active agents and organizations. Basically, it is both a yellow pages service, and a green pages service descriptor.

- Organization Management System (OMS): mainly responsible for the management of the organizations and their entities, thus allowing for the creation and management of any organization.

- Platform Kernel (PK): maintains basic management services for an agent platform.

The following sections describe the different components of the THOMAS architecture in greater detail.

\subsection{Service Facilitator}

The Service Facilitator (SF) is a mechanism and support by which organizations and agents can offer and find services. The SF provides a place in which the autonomous entities can register service descriptions as directory entries.

The SF acts as a gateway to access the THOMAS platform. It manages this access transparently, by means of security techniques and access rights management. The SF can find services by searching for a given service profile or searching for the goals that can be fulfilled when executing the service. This is done by using the matchmaking (Sycara, Widoffand, Klusch, \& Lu, 1982) and service composition mechanisms (Corchado \& Laza, 2003) which are provided by the SF. The SF also acts as a yellow pages manager and in this way it can find which entities provide a given service.

A service represents an interaction of two entities, which is modelled as communication among independent processes. Services can be described as offering capabilities, each of which enables the fulfilment of a given goal. The service may have some preconditions, which need to be true for the service execution. Moreover, both service client and provider exchange one or more input and output messages during the service execution, which affects their environment. There could also be additional parameters in a service description, which are independent of the service functionality (non-functional parameters), such as quality of service, deadlines and security protocols. Finally, the service results can be enhanced using automatic service composition mechanisms (Klusch, Fries, \& Sycara, 2006; Brogi, Corfini, \& Popescu, 2005) (for example, partial matchmaking). To do this the SF stores the description of the internal processes that are executed when the service is running.

In our case, multi-agent technology provides us with FIPA communication protocols which are well established mechanisms for standardizing the interactions. Thus, every service has an associated protocol. In cases where the service requires the execution of a chain of protocols, the service is marked as "complex". Given that THOMAS works with semantic services, another important piece of data is the ontology used in the service. Thus, when the service description is accessed, any entity will have all of the information necessary in order to interact with the service and make an application that can use this service. Such a description can also be employed for pre-compiled services, in which the process model of the service is composed of the sequence of the elementary services to be executed, instead of the internal processes of this service.

Normally, a service can be supplied by more than one provider in the system. Therefore, a service has an associated list of providers. All providers can offer exact copies of the service, given that they share a common implementation of the service. Or they may share only the interface and each provider may implement the service in a different way. This is easily achieved in THOMAS

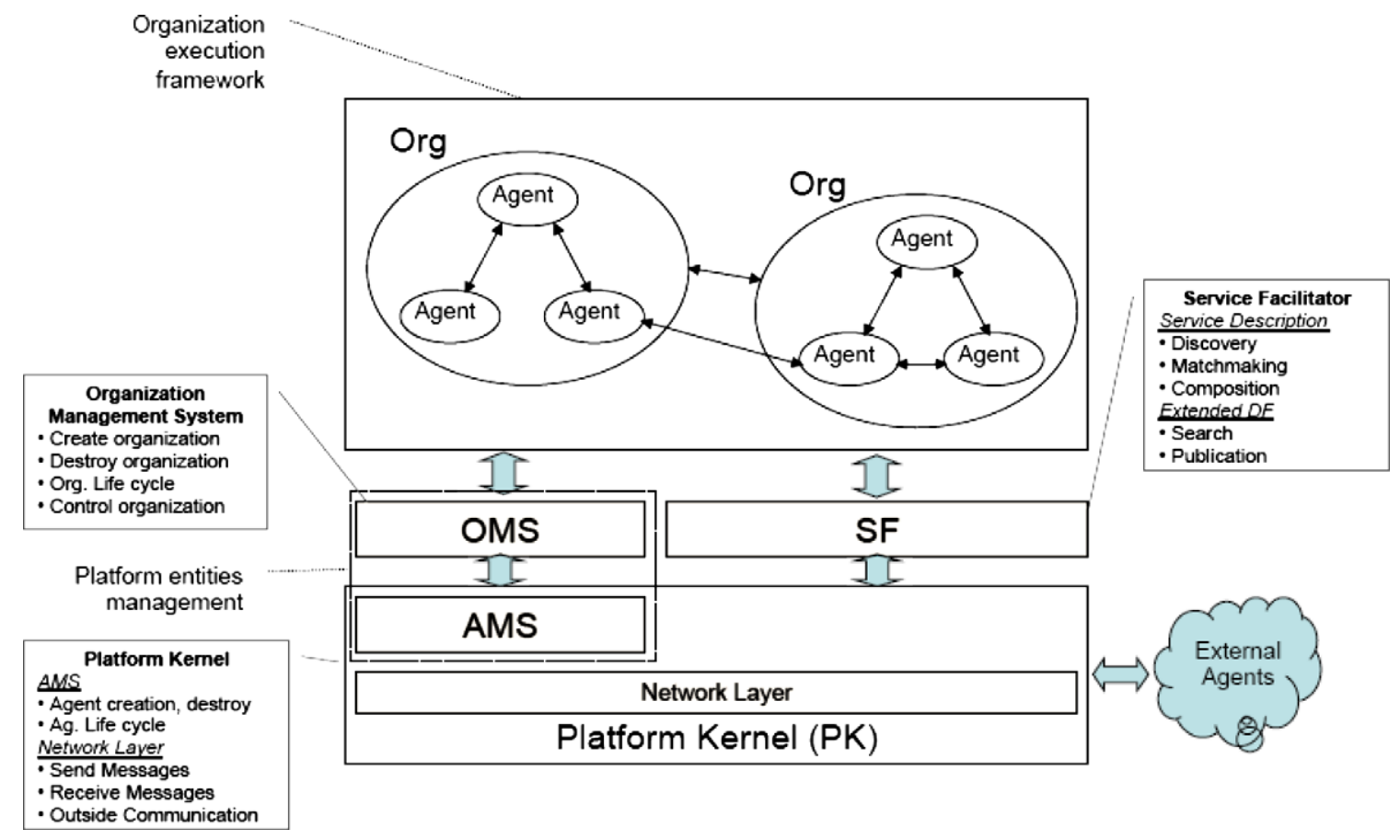

Fig. 1. THOMAS architecture. 
because the general service profile is separate from the service process.

A service is defined as a tuple (sID, goal, prof, proc, ground, ont):

- sID is a unique service identifier;

- goal is the final purpose of the service and provides the first abstraction level for service composition;

- prof is the service profile which describes the service in terms of its IOPEs (Inputs, Outputs, Preconditions and Effects) and nonfunctional attributes, in a readable way for those agents searching for information (or matchmaking agents which act as searching service agents). This type of representation includes a description of what the service fulfils, the constraints to its applicability and quality of service, and the requirements that clients have to satisfy in order to use the service.

- proc describes how a client has to use the service; it specifies the semantic content for using the service, the situations in which it is obtained, and, whenever required, the step-by-step processes to get these results. In other words, it specifies how to call a service and what should happen when the service is executed.

- ground specifies in detail how an agent can access the service. Grounding specifies a communication protocol, the message formats, the contact port and other specific details of the service. It is specified using the OWL-S standard extended with FIPA protocols.

- ont is the ontology that gives meaning to all of the elements of the service. OWL-DL is the chosen language.

This proposal is based on OWL-S specification for semantic web services, extended when it is necessary to empower its functionality. Goals, preconditions and effects (or post-conditions) are logical formulas.

The tuple defined above for service specification is implemented in two parts: the abstract service, general for all providers; and the concrete service, with the implementation details. As such, services are stored within the system and split into two parts: the service profile (which represents the abstract service specification) and a set of service process specifications (which detail the specific service). Thus, in THOMAS services are implemented as the following tuple, in which its elements are OWL-S extended specifications:

\section{$<$ ServiceID, Providers, ServGoal, ServProfile> Providers:: $=\quad<$ ProvIDList, ServImpID, ServProcess,
ServGround $>$$$
\text { ProvIDList::= ProviderID }
$$ \\ where}

- Providers are a set of tuples composed of a Providers identifier list (ProvIDList), the service process model specification (ServProcess), and its particular instantiation (ServGround).

- ProvIDList stores a list of service provider identifiers.
The SF supplies a set of standard services (meta-services) to manage the services provided by organizations or individual agents (see Table 1). These meta-services also have to be used by the remaining THOMAS components (OMS and PK) to advertise their own services. SF meta-services can be classified in three types:

- Registration: allowing the addition, modification and removal of services from the SF directory.

- Affordability: for managing the association between providers and their services.

- Discovery: for searching and composing services as an answer to user requirements.

Their functionality is so complex that they can be delegated to a specialized component.

\subsection{Organization Management System}

The Organization Management System (OMS) is in charge of organization life-cycle management, including specification and administration of both its structural components (roles, units and norms) and its execution components (participant agents and roles they play, and active organizational units). Organizations are structured by means of organizational units, which represent groups of entities (agents or other units), which coordinate in order to pursue a common goal. These organizational units have an internal topology (i.e., hierarchical, team, plain), which imposes restrictions on agent relationships and control (e.g., supervision or information relationships).

In THOMAS, a "virtual" unit has been defined in order to represent the "world" system in which agents participate by default. The OMS creates organizations within this "virtual" unit by registering organizational units which can in turn be composed of more units. Moreover, roles are defined in each unit. They represent all of the functionality needed to achieve the unit goal. They might also have associated norms for controlling role actions (i.e., which of the services agents playing that role are allowed to request, offer or serve; permissions for accessing resources). As a result, agents can dynamically adopt roles within units. As such, the OMS controls this role adoption process and determines which entities play each role through time.

The OMS component makes use of the following information:

- UnitList: stores existing units, together with their objectives, topology and parent unit.

- RoleList: stores the list of roles defined in each unit and their attributes (accessibility, visibility, position and inheritance). Accessibility indicates whether a role can be adopted by an agent on demand; visibility indicates whether agents can obtain

Table 1

SF meta-services.

\begin{tabular}{lll}
\hline Type & Meta-service & Description \\
\hline Registration & RegisterProfile & Creates a new service description (profile) \\
& RegisterProcess & Creates a particular implementation (process) for a service \\
& ModifyProfile & Modifies an existing service profile \\
& DeregisterProfile & Modifies an existing service process \\
Affordability & AddProvider & Removes a service description \\
& RemoveProvider & Adds a new provider to an existing service process \\
Discovery & SearchService & Removes a provider from a service process \\
& GetProfile & Searches a service (or a composition of services) that satisfies the user requirements \\
& GetProcess & Gets the description (profile) of a specific a service \\
& & Gets the implementation (process) of a specific a service
\end{tabular}


information from this role on demand; position indicates whether it is a supervisor, subordinate or member of the unit; and inheritance indicates its parent role.

- NormList: stores norms defined in the system.

- EntityPlayList: describes <entity, unit, role> association, i.e., which roles have been adopted by an entity (agent) within each unit.

The OMS offers all of the services needed for a suitable organization performance. These services are classified as: structural services, which modify the structural and normative organization specification; and dynamical services, which allow agents to enter or leave the organization dynamically, and to adopt roles. The complete list of OMS services is detailed in Table 2 . These services are briefly described as follows.

\subsubsection{Structural services}

The OMS provides a group of services for registering or deregistering structural components, specific roles, norms and units. It also offers services for reporting on these components.

As previously explained, a role represents a position within the unit in which it is defined. It is related to some interaction norms, imposed by the unit structure and its specific position within the unit, as well as to some behaviour norms, which specify its functionality (services that it needs and offers), restrict its actions (prohibition, obligations and permissions) and establish the consequences of these norms (sanctions and rewards).

Therefore, a norm indicates the obligations, permissions and prohibitions of roles related to service registry, request and fulfilment; service composition or quality of service results. In this way, a norm defines restrictions that cannot be expressed by means of service preconditions or post-conditions.

Finally, a unit represents groups of agents and establishes the topological structure of the system. It is also a recursive concept, so units can be defined within other units. It enables the representation of organizational structures like hierarchy, matrix, coalition, etc. (Argente et al., 2007). Furthermore, it indicates what the structural positions of the system are (i.e. member, supervisor, subordinate), as well as the relationships among these positions imposed by the structure.

The OMS establishes a hierarchy of roles, so any agent that plays a specific role is enabled to request or offer services related to superior hierarchical roles, provided that organizational norms do not explicitly forbid it.

Through the publication of the structural services, the OMS allows the modification of some aspects related to the organization structure, norm and functionality at execution time. For example, a specific agent of the organization can be allowed to add new norms, roles or units during system execution. These types of services should be restricted to the internal roles of the system, which have a level of permission high enough to perform these kinds of operations (i.e. supervisor role). Moreover, these services might not be published in the SF in some specific applications in which the system structure must not be dynamically modified.

Optionally, more complex services for updating organization components can be offered by means of the composition of the services above. For example, a complex service which offers the inclusion of a new role indicating its name attributes and related norms; or a complex service for unit creation which allows the creation of an empty unit with its associated norms and roles. Moreover, services for modifying component features might also be offered. For example, a service for changing the visibility value of a specific role.

Another type of structural service is information services, which provide specific information on all of the components of the organization. They might be restricted to some internal roles of the system. Furthermore, if the OMS is the only component which uses those services, then they are not directly published in the SF.

\subsubsection{Dynamic services}

The OMS offers a set of basic services for dynamic role adoption and the entry/exit of unit members, which are not directly accessible to agents, but are combined through compound services.

The OMS also offers a set of compound services that can be used by agents for adopting roles, leaving them, and applying sanctions.

As previously explained, the OMS is responsible for managing the life-cycle of the organizations. Thus, it includes meta-services for defining structural components of organizations, i.e. roles, units and norms. These structural components could be dynamically modified over the lifetime of the organization. Moreover, the OMS includes services for creating new organizations (i.e. creating new units), admitting new members within those organizations (i.e. acquiring roles) and resigning members (i.e. expulsing or leaving roles). The management of the agent life-cycle is done by the PK component, which is explained in the following section.

Table 2

OMS meta-services.

\begin{tabular}{|c|c|c|c|}
\hline Type & Subtype & Meta-service & Description \\
\hline \multirow{13}{*}{ Structural } & \multirow[t]{6}{*}{ Registration } & RegisterRole & Creates a new role within a unit \\
\hline & & RegisterNorm & RegisterNorm includes a new norm within a unit \\
\hline & & RegisterUnit & Creates a new unit within a specific organization \\
\hline & & DeregisterRole & Removes a specific role description from a unit \\
\hline & & DeregisterNorm & Removes a specific norm description \\
\hline & & DeregisterUnit & Removes a unit from an organization \\
\hline & \multirow[t]{7}{*}{ Information } & InformAgentRole & Indicates roles adopted by an agent \\
\hline & & InformMembers & Indicates entities that are members of a specific unit \\
\hline & & QuantityMembers & Provides the number of current members of a specific unit \\
\hline & & InformUnit & Provides unit description \\
\hline & & InformUnitRoles & Indicates which roles are the ones defined within a specific unit \\
\hline & & InformRoleProfiles & Indicates all profiles associated to a specific role \\
\hline & & InformRoleNorms & Provides all norms addressed to a specific role \\
\hline \multirow[t]{6}{*}{ Dynamic } & \multirow[t]{3}{*}{ Basic } & RegisterAgentRole & Creates a new <entity, unit, role> \\
\hline & & DeregisterAgentRole & relationship \\
\hline & & & Removes a specific <entity, unit, role> relation \\
\hline & \multirow[t]{3}{*}{ Compound } & AcquireRole & Requests the adoption of a specific role within a unit \\
\hline & & LeaveRole & Requests to leave a role \\
\hline & & Expulse & Forces an agent to leave a specific role \\
\hline
\end{tabular}




\subsection{Platform Kernel}

The Platform Kernel (PK) is in charge of providing the usual services required in a multi-agent platform. Therefore, it is responsible for managing the life-cycle of the agents included in the different organizations, and it also makes it possible to have a communication channel (incorporating several message transport mechanisms) to facilitate interaction among entities. The PK also provides safe connectivity and the mechanisms necessary for allowing multi-device interconnectivity.

A previous security mechanism is implemented for some of the services described below, which permits the management of who can invoke each service and over whom. For example, the supervisor of an organization may have the option of creating new agents within its organization. For this, the agent Register Service should be invoked at the platform kernel level.

The services offered must be FIPA legacy, with some modifications. The PK services needed in a THOMAS infrastructure are clas-

Table 3

PK services.

\begin{tabular}{|c|c|c|}
\hline Type & $\begin{array}{l}\text { Meta- } \\
\text { service }\end{array}$ & Description \\
\hline Registration & $\begin{array}{l}\text { Register } \\
\text { Deregister } \\
\text { Update } \\
\text { register }\end{array}$ & $\begin{array}{l}\text { Registers a new agent in the platform } \\
\text { Eliminates an agent registration } \\
\text { Modifies the information appearing in an } \\
\text { agent register (except the agent name) }\end{array}$ \\
\hline Discovery & $\begin{array}{l}\text { Agent } \\
\text { Search } \\
\text { Get } \\
\text { description }\end{array}$ & $\begin{array}{l}\text { Requests information from a registered } \\
\text { agent in the platform } \\
\text { Obtains the platform description }\end{array}$ \\
\hline Management & $\begin{array}{l}\text { Suspend } \\
\text { Activation }\end{array}$ & $\begin{array}{l}\text { Suspends the execution of a specific agent } \\
\text { Activates the execution of an agent that is } \\
\text { currently suspended }\end{array}$ \\
\hline Communication & Send & $\begin{array}{l}\text { Sends a message to any agent in the platform } \\
\text { or outside }\end{array}$ \\
\hline
\end{tabular}

sified into four types as shown in Table 3: (i) Registration: services for adding, modifying and removing native agents from the platform. (ii) Discovery: services for getting information about the native agents active in the platform. (iii) Management: services for controlling the activation state of native agents in the platform. (iv) Communication: services for communicating with agents in the platform and outside.

The THOMAS proposal does not pursue the development of a new multi-agent platform kernel. The services required are a sub-

Table 4

Initial content of UnitList for structural specification of the system.

\begin{tabular}{llll}
\hline UnitName & ParentUnit & Goal & Type \\
\hline Virtual (world) & - & - & Flat \\
HomeCare & Virtual & HomeCare & Congregation \\
HCServiceUnit & HomeCare & HomeCareService & Flat \\
LocationUnit & HomeCare & HomeCareLocation & Flat \\
AlertUnit & HomeCare & HomeCareAlert & Flat \\
\hline
\end{tabular}

Table 5

Initial content of RoleList.

\begin{tabular}{lllll}
\hline RoleName & inUnit & Accesibility & Position & Inheritance \\
\hline Patient & HomeCare & Public & Member & - \\
Doctor & HomeCare & Public & Member & - \\
Provider & HomeCare & Public & Member & - \\
Family & HomeCare & Private & Member & - \\
HCServicePatient & HCServideUnit & Public & Member & Patient \\
HCServiceProvider & HCServideUnit & Public & Member & Provider \\
HCServiceDoctor & HCServideUnit & Public & Member & Doctor \\
LocationPatient & LocationUnit & Public & Member & Patient \\
LocationProvider & LocationUnit & Public & Member & Provider \\
LocationDoctor & LocationUnit & Public & Member & Doctor \\
AlertPatient & AlertUnit & Public & Member & Patient \\
AlertProvider & AlertUnit & Public & Member & Provider \\
AlertDoctor & AlertUnit & Public & Member & Doctor \\
\hline
\end{tabular}

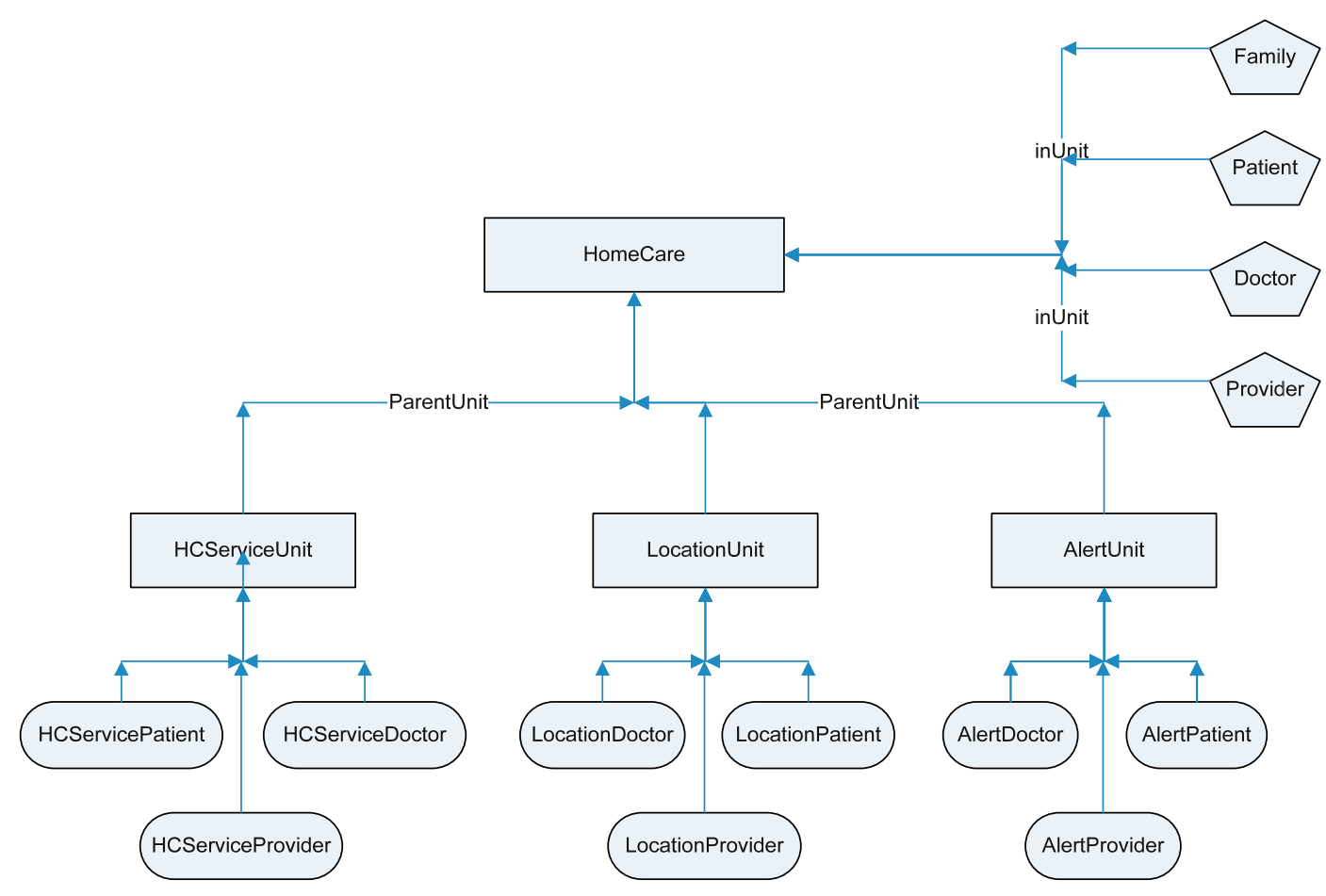

Fig. 2. Home Care structure (units and roles). 
set of the services typically offered by diverse, well-known agent platforms. Therefore, PK functionalities can be provided by any agent platform which offers the minimum services mentioned above. Moreover, the chosen agent platform must offer an appro- priate communication mechanism which at the very least offers FIPA compatibility.

In summary, this section has described the main components of the THOMAS architecture focusing on their functionalities and

Table 6

Service profiles for the HomeCare system.

\begin{tabular}{|c|c|c|}
\hline \multicolumn{3}{|l|}{ Profiles of HCServiceUnit } \\
\hline $\begin{array}{l}\text { Service: OpenCloseDoor } \\
\text { UnitID: HCServiceUnit } \\
\text { Inputs: } \\
\text { iddoor: string } \\
\text { operation: string }\end{array}$ & $\begin{array}{l}\text { ProfileID: OpenCloseDoorPF } \\
\text { ClientRole: HCServicePatient } \\
\text { Outputs: [door ok] } \\
\text { iddoor: string } \\
\text { state: string }\end{array}$ & $\begin{array}{l}\text { Description: Open or close a door } \\
\text { ProviderRole: HCServiceProvider } \\
\text { Outputs: [not ok door] } \\
\text { error }\end{array}$ \\
\hline $\begin{array}{l}\text { Service: OnOffLight } \\
\text { UnitID: HCServiceUnit } \\
\text { Inputs: } \\
\text { idlight: string } \\
\text { operation: string }\end{array}$ & $\begin{array}{l}\text { ProfileID: OnOffLightPF } \\
\text { ClientRole: HCServicePatient } \\
\text { Outputs: [light ok] } \\
\text { idlight: string } \\
\text { state: string }\end{array}$ & $\begin{array}{l}\text { Description: On or off a light } \\
\text { ProviderRole: HCServiceProvider } \\
\text { Outputs: [not ok light] } \\
\text { error }\end{array}$ \\
\hline $\begin{array}{l}\text { Service: LockUnlockAccess } \\
\text { UnitID: HCServiceUnit } \\
\text { Inputs: } \\
\text { idaccess: string } \\
\text { operation: string }\end{array}$ & $\begin{array}{l}\text { ProfileID: LockUnlockAccessPF } \\
\text { ClientRole: HCServicePatient } \\
\text { Outputs: [access ok] } \\
\text { idaccess: string } \\
\text { state: string }\end{array}$ & $\begin{array}{l}\text { Description: Lock or unlock an access } \\
\text { ProviderRole: HCServiceProvider } \\
\text { Outputs: [not ok access] } \\
\text { error }\end{array}$ \\
\hline $\begin{array}{l}\text { Service: OnOffHeating } \\
\text { UnitID:HCServiceUnit } \\
\text { Inputs: } \\
\text { idheating: string } \\
\text { operation: string } \\
\text { temperature: string }\end{array}$ & $\begin{array}{l}\text { ProfileID: OnOffHeatingPF } \\
\text { ClientRole: HCServicePatient } \\
\text { Outputs: [heating ok] } \\
\text { idheating: string } \\
\text { state: string } \\
\text { temperature: string }\end{array}$ & $\begin{array}{l}\text { Description: On or off the heating } \\
\text { ProviderRole:HCServiceProvider } \\
\text { Outputs: [not ok heating] } \\
\text { error }\end{array}$ \\
\hline $\begin{array}{l}\text { Service: OnOffAirCond } \\
\text { UnitID: HCServiceUnit } \\
\text { Inputs: } \\
\text { idair: string } \\
\text { operation: string } \\
\text { temperature: string }\end{array}$ & $\begin{array}{l}\text { ProfileID: OnOffAirCondPF } \\
\text { ClientRole: HCServicePatient } \\
\text { Outputs: [aircond ok] } \\
\text { idair: string } \\
\text { state: string } \\
\text { temperature: string }\end{array}$ & $\begin{array}{l}\text { Description: On or off the air conditioning } \\
\text { ProviderRole: HCServiceProvider } \\
\text { Outputs: [not ok aircond] } \\
\text { error }\end{array}$ \\
\hline $\begin{array}{l}\text { Service: UpDownBlind } \\
\text { UnitID:HCServiceUnit } \\
\text { Inputs: } \\
\text { idblind: string } \\
\text { operation: string }\end{array}$ & $\begin{array}{l}\text { ProfileID: UpDownBlind PF } \\
\text { ClientRole: HCServicePatient } \\
\text { Outputs: [blind ok] } \\
\text { idblind: string } \\
\text { state: string }\end{array}$ & $\begin{array}{l}\text { Description: Up or down a blind } \\
\text { ProviderRole: HCServiceProvider } \\
\text { Outputs: [not ok blind] } \\
\text { error }\end{array}$ \\
\hline \multicolumn{3}{|l|}{ Profiles of LocationUnit } \\
\hline $\begin{array}{l}\text { Service: SearchPatient } \\
\text { UnitID: LocationUnit } \\
\text { Inputs: } \\
\text { idhome: string } \\
\text { idpatient: string }\end{array}$ & $\begin{array}{l}\text { ProfileID: SearchPatientPF } \\
\text { ClientRole: LocationProvider, LocationDoctor, Family } \\
\text { Outputs: [patient ok] } \\
\text { name: string } \\
\text { location: string }\end{array}$ & $\begin{array}{l}\text { Description: Search for a patient in their home } \\
\text { ProviderRole: LocationProvider } \\
\text { Outputs: [not in home] } \\
\text { error }\end{array}$ \\
\hline $\begin{array}{l}\text { Service: IdentifyPatient } \\
\text { UnitID: LocationUnit } \\
\text { Inputs: } \\
\text { idpatient: string }\end{array}$ & $\begin{array}{l}\text { ProfileID: SearchPatientPF } \\
\text { ClientRole: LocationProvider } \\
\text { Outputs: [patient ok] } \\
\text { location: string } \\
\text { date: time }\end{array}$ & $\begin{array}{l}\text { Description: Identify a patient } \\
\text { ProviderRole: LocationProvider } \\
\text { Outputs: [not ok patient] } \\
\text { error }\end{array}$ \\
\hline \multicolumn{3}{|l|}{ Profiles of AlertUnit } \\
\hline $\begin{array}{l}\text { Service: SendSms } \\
\text { UnitID: AlertUnit } \\
\text { Inputs: } \\
\text { sms: string } \\
\text { phone: string }\end{array}$ & $\begin{array}{l}\text { ProfileID: SendSmsPF } \\
\text { ClientRole: AlertProvider, AlertDoctor, Family, AlertPatient } \\
\text { Outputs: [phone ok] } \\
\text { idsms: string } \\
\text { state: string }\end{array}$ & $\begin{array}{l}\text { Description: Send a SMS } \\
\text { ProviderRole: AlertProvider } \\
\text { Outputs: [not ok phone] } \\
\text { error }\end{array}$ \\
\hline $\begin{array}{l}\text { Service: SendMms } \\
\text { UnitID: AlertUnit } \\
\text { Inputs: } \\
\text { mms: data mms } \\
\text { phone: string }\end{array}$ & $\begin{array}{l}\text { ProfileID: SendMmsPF } \\
\text { ClientRole: AlertProvider, AlertDoctor, Family,AlertPatient } \\
\text { Outputs: [phone ok] } \\
\text { idmms: string } \\
\text { state: string }\end{array}$ & $\begin{array}{l}\text { Description: Send a MMS. } \\
\text { ProviderRole: AlertProvider } \\
\text { Outputs: [not ok phone] } \\
\text { error }\end{array}$ \\
\hline $\begin{array}{l}\text { Service: ProcessSms } \\
\text { UnitID: AlertUnit } \\
\text { Inputs: } \\
\text { sms: string } \\
\text { phone: string }\end{array}$ & $\begin{array}{l}\text { ProfileID: ProcessSmsPF } \\
\text { ClientRole: AlertProvider, AlertDoctor, Family, AlertPatient } \\
\text { Outputs: [sms ok] } \\
\text { sms: string } \\
\text { phone: string }\end{array}$ & $\begin{array}{l}\text { Description: Process a SMS } \\
\text { ProviderRole: AlertProvider } \\
\text { Outputs: [not ok sms] } \\
\text { error }\end{array}$ \\
\hline $\begin{array}{l}\text { Service: SendMail } \\
\text { UnitID: AlertUnit } \\
\text { Inputs: } \\
\text { email: string } \\
\text { subject: string } \\
\text { body: string } \\
\text { adj: data }\end{array}$ & $\begin{array}{l}\text { ProfileID: SendMailPF } \\
\text { ClientRole: AlertProvider, AlertDoctor, Family, AlertPatient } \\
\text { Outputs: [email ok] } \\
\text { idsms: string } \\
\text { state: string }\end{array}$ & $\begin{array}{l}\text { Description: Send a mail } \\
\text { ProviderRole: AlertProvider } \\
\text { Outputs: [not ok email] } \\
\text { error }\end{array}$ \\
\hline
\end{tabular}


describing the services which form the interface with each one of these components. The following section presents a detailed example employing the services described above.

\section{Applying THOMAS to Home Care}

Home Care facilitates the interconnection between dependent people and their environment and medical staff (doctors, nurses and personal assistant), delimiting services that each one can request or offer. The system controls which services must be provided by each agent. The internal functionality of these services is the responsibility of provider agents. However, the system imposes some restrictions regarding service profiles, service request orders and service results.

A description of the structure elements of the Home Care organization is detailed below. Then, in Section 4.2, a dynamical usage of the organization is explained, providing different execution scenarios.

\subsection{Cases-study organization structure}

This case study is modelled as an organization (HomeCare) within which there are three organizational units (HCServiceUnit, LocationUnit and AlertUnit) each of which represents a group of agents. The units are dedicated to Home Care services, location services and alert services, respectively.

Four kinds of roles can interact in the Home Care case study: patient, doctor, family and provider. The Patient role requests system services. The Patient role can request home automation services through the alert service. This role also communicates with the medical service or family, and other services in the home. The Doctor role consists of three specialized sub-roles according to the type of communication with each unit (HCServiceDoctor, LocationDoctor and AlertDoctor). The Provider role is in charge of performing services. A provider agent offers home automation, location or alert search services. The Provider role also consists of three specialized sub-roles: HCServiceProvider, LocationProvider and AlertProvider. Finally, the Family role provides advanced consulting services. It represents the family where relatives can check the patient status. As it is a private role, agents are not able to access this Family role. Fig. 2 shows the Home Care structure, with its units, roles and interrelationships

The OMS component stores the list of defined units (UnitList, Table 4) and the list of roles (RoleList, Table 5) internally.

The HomeCare organization offers three services: Automation, Location and Alert service. These services are specialized for each unit. A brief description of the profiles of each of these services is shown in Table 6.

All of these services have been registered in the SF component of the THOMAS platform. In this example, we have assumed that the Home Care system does not initially have an agent registered as a service provider, any agent acting as a patient, or any agent acting as a doctor. Therefore, this system has initially only been structured as a regulated space in which agents might enter to provide or request any of those specific services registered in the SF component. Consequently, in the initial state of the system, there is no provider attached to the HomeCare services.

In the following section, different scenarios are considered in which patient and/or provider and/or doctor agents enter and participate in the system.

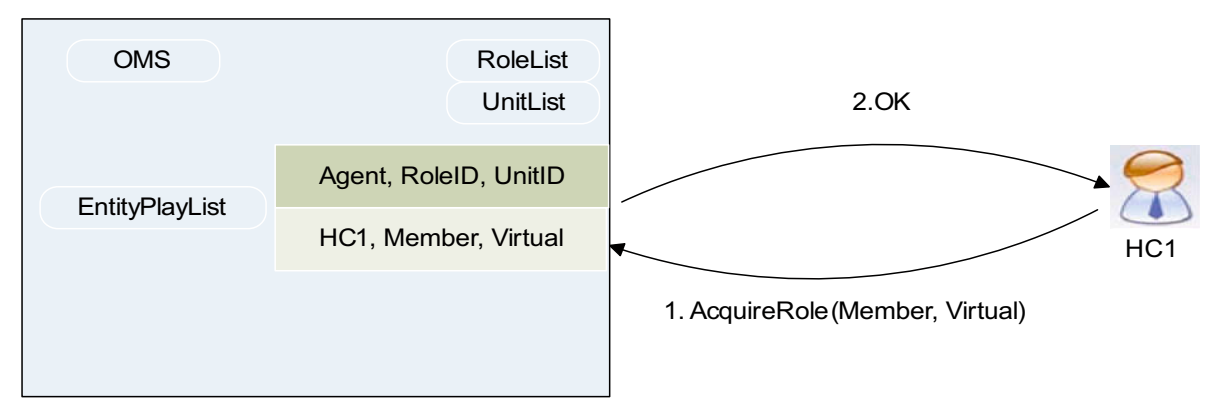

Fig. 3. Example of agent registration.

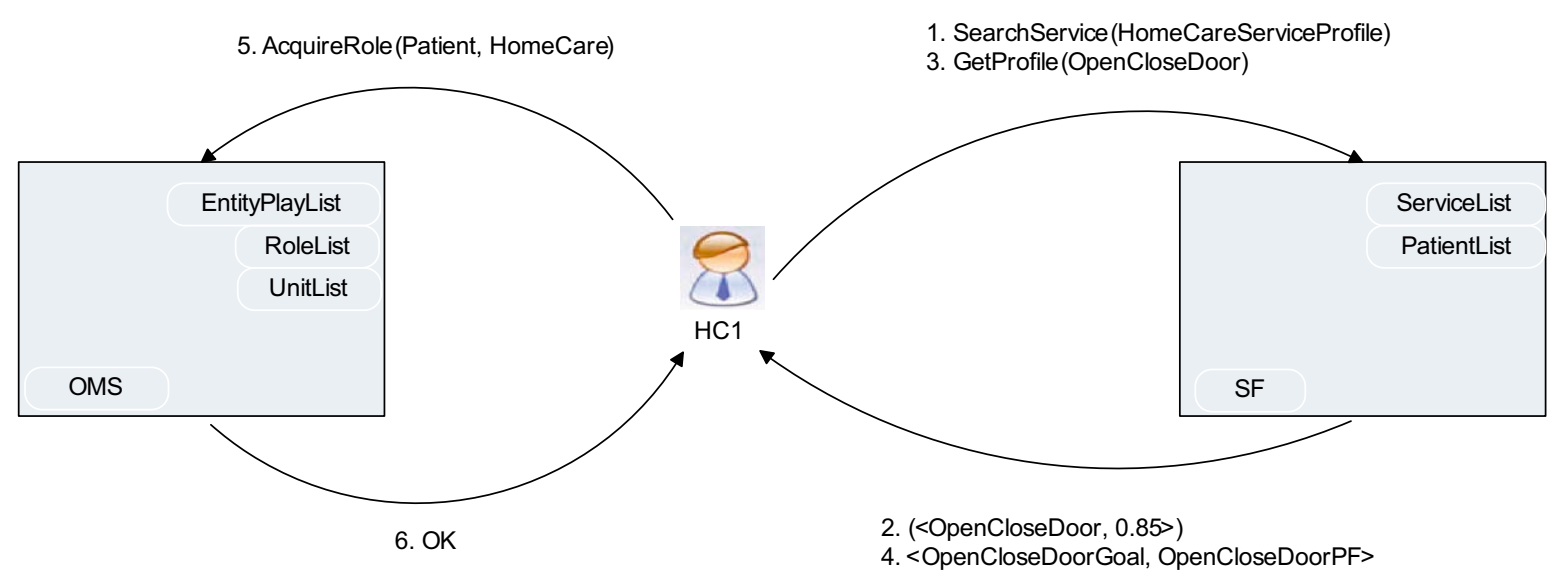

Fig. 4. Example of patient registration. 


\subsection{System dynamics}

In this section, the use of THOMAS meta-services in the HomeCare case study is presented in detail. System dynamics are shown through the specification of different scenarios: (i) an agent joins the THOMAS platform; (ii) a Patient is registered; (iii) the Patient is registered as a PatientLocation; (iv) a new service implementation is defined; (v) new service patients are included; (vi) a doctor is registered; (vii) services are requested; (viii) malicious agents are expulsed; (ix) a Provider is deregistered; and (x) a new unit is created.

\subsubsection{Agent registration}

This scenario details the sequence of services that an agent should request in order to join the THOMAS platform. In Fig. 3, $\mathrm{HC} 1$ is an agent that represents a home automation provider. Its functionality allows it to offer services belonging to its company. Agents join THOMAS platform by placing a request with the OMS for membership of the virtual organization, using AcquireRole service (Fig. 3, message 1).

The OMS checks all restrictions (existence of unit and role identifiers, role compatibility, etc.) and registers HC1 agent as a new member of the THOMAS platform. The OMS makes use of RegisterAgentRole service to add this agent-role adoption to EntityPlayList.

\subsubsection{Patient registration}

In this scenario, the process for registering a new Patient is detailed (Fig. 4). Once HC1 has been registered as a member of the THOMAS platform, it asks SF which defined services have a profile similar to its own "Home Care service". This request is carried out using the SF SearchService (Fig. 4, message 1), in which HomeCareServiceProfile corresponds to the profile of the patient search service implemented by HC1.

The SF returns service identifiers that satisfy these search requirements together with a ranking value for each service (message 2). Ranking value indicates the degree of suitability between a service and a specified service purpose. Then HC1 executes GetProfile (message 3 ) in order to obtain detailed information about the OpenCloseDoor service. Service outputs are "service goal" and "profile" (message 4). The OpenCloseDoor profile specifies that service providers have to play a Patient role within HCService. Thus, HC1 requests the AcquireRole service from the OMS in order to acquire this patient role (message 5). AcquireRole service is carried out

\begin{tabular}{|c|c|}
\hline \multirow{2}{|c|}{ searchPatientProcess } \\
\hline \multirow{2}{*}{ process:hasInput $=$} & ?idhome \\
\cline { 2 - 2 } process:hasOutput $=$ & ?idpatient \\
\cline { 2 - 2 } & ?name \\
\hline \multirow{2}{*}{ process:hasDoctor $=$} & locationDoctor \\
\cline { 2 - 2 } & process:TheDoctor \\
\hline \multirow{2}{*}{ process:performedBy $=$} & locationDoctor \\
\cline { 2 - 2 } & ch1.thomas \\
\cline { 2 - 2 } & process:TheServer \\
\hline service:describes $=$ & searchPatientService \\
\hline
\end{tabular}

Fig. 7. Example of SearchPatient process.

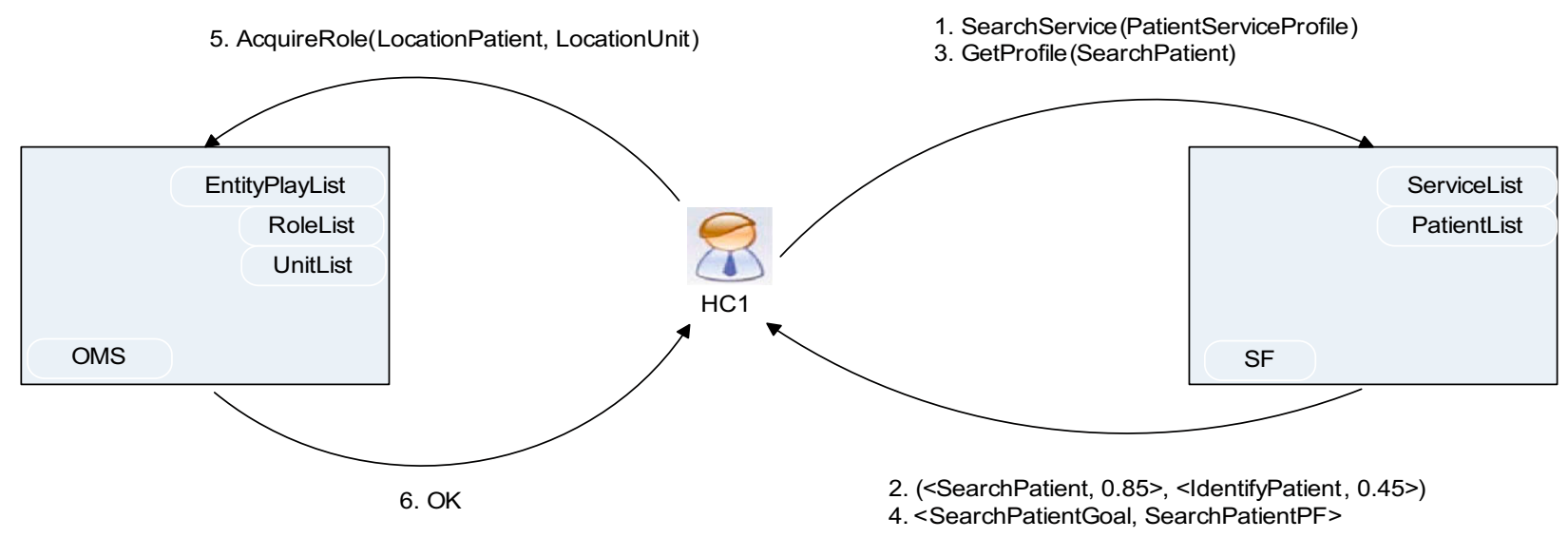

Fig. 5. Example of LocationPatient registration.

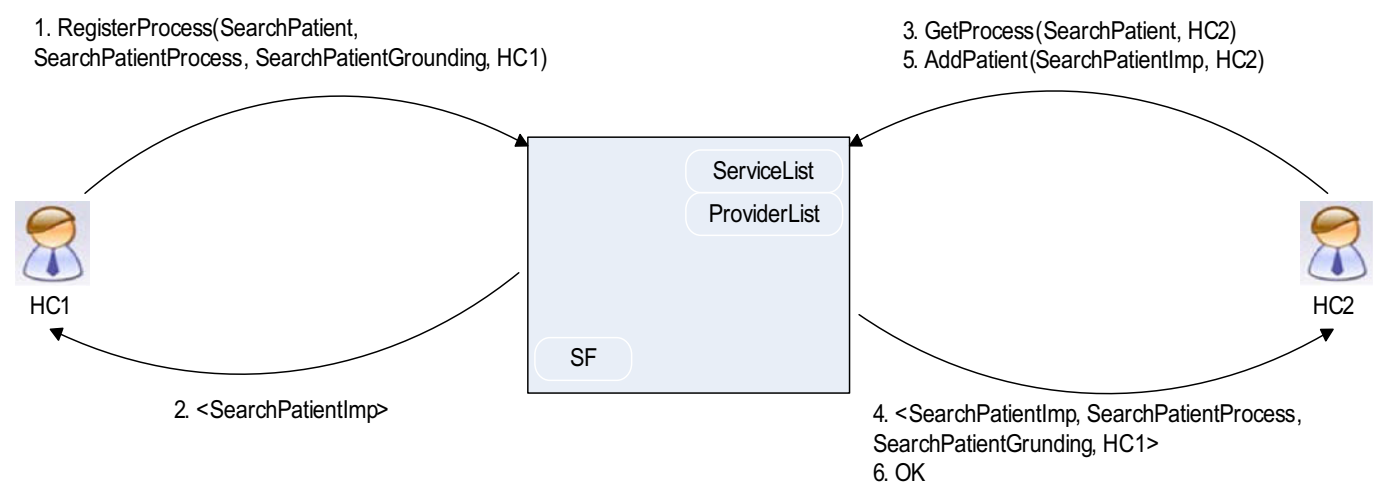

Fig. 6. Example of service implementation and patient registration. 
successfully (message 6), because HCService is accessible from Virtual organization, thus HC1 is registered as a Patient.

\subsubsection{LocationPatient registration}

Once the "patient registering" process has been detailed, the registration of a location patient is illustrated (Fig. 5). HC1 is able to provide a search patient in the Home Care domain. Therefore, it asks SF whether an available service description with a closer profile exists, requesting SearchService from SF as before (Fig. 5, message 1).
In this case, SF returns both SearchPatient and IdentifyPatient since these two services are visible within HomeCare unit. As indicated in the service result, IdentifyPatient service is more appropriate for $\mathrm{HC} 1$ functionality. Therefore, $\mathrm{HC} 1$ requests information about this service from SF, using GetProfile (message 3). The IdentifyPatient profile returned (message 4) specifies that service providers must place LocationPatients within LocationUnit. Then HC1 places a request with OMS to adopt LocationPatient role (message 5 ). AcquireRole service is carried out successfully (message 6), so HC1 agent is registered as a LocationProvider.

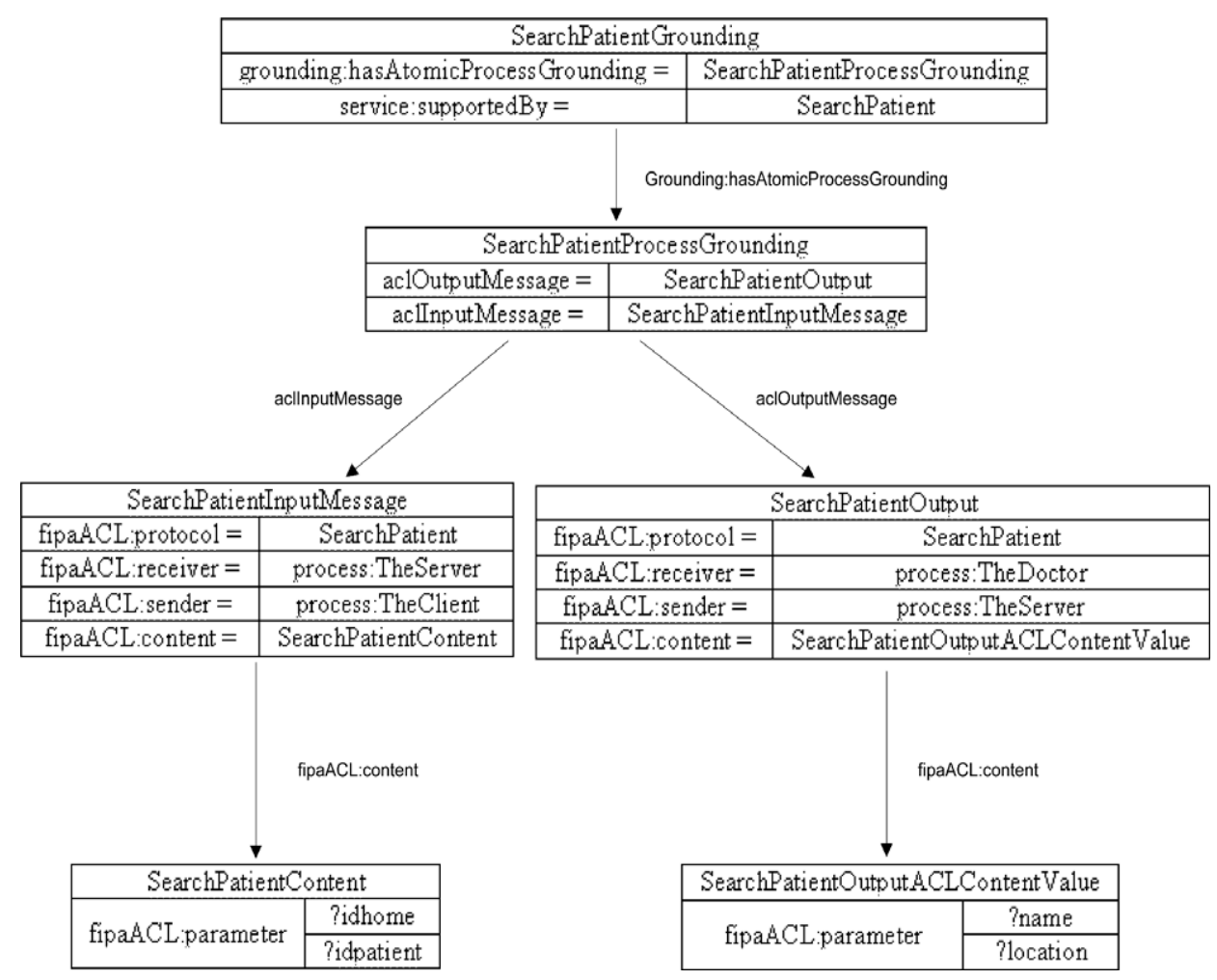

Fig. 8. Example of SearchPatient grounding.

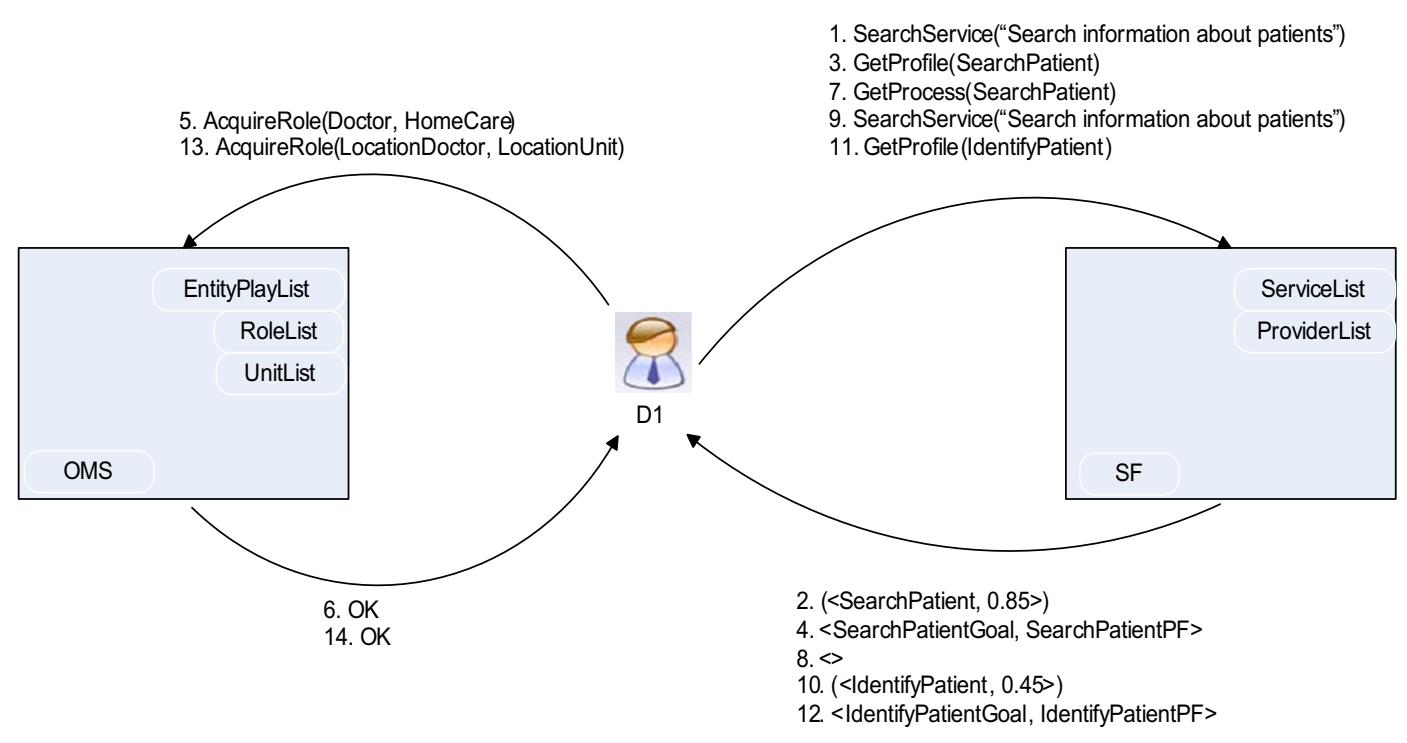

Fig. 9. Example of doctor registration. 


\subsubsection{Registering a new service implementation}

In this example, the sequence of actions that allows an agent to register its own implementation of a service is explained in detail (Fig. 6). In this case, HC1 has already adopted LocationPatient role and is interested in providing its own implementation of SearchPatient service. Therefore it registers itself as service provider in SF, employing RegisterProcess service (Fig. 6, message 1), in which SearchPatientProcess and SearchPatientGrounding correspond to service process and grounding, respectively. Fig. 7 contains the specification of SearchPatient service process. Fig. 8 shows SearchPatient grounding. This type of grounding specifies how a service can be requested by means of sending ACL messages.

\subsubsection{Adding new service patient}

This section demonstrates how another LocationPatient (HC2) is added to a service patient list (Fig. 6). In this example, HC2 has already adopted the LocationPatient role and $\mathrm{HC} 1$ has been registered as a provider of the SearchPatient service. HC2 initially asks what the registered implementations of SearchPatient service are (Fig. 6, message 3). SF provides a list that contains service implementations details (message 4). HC2 decides to employ the same service process as $\mathrm{HC1}$, so it uses AddPatient service in order to request its inclusion as a provider of SearchPatient service (Fig. 6, message 5).

\subsubsection{Doctor registration}

The following scenario shows the set of service calls for registering new agents as service doctors within the HomeCare (Fig. 9). A new doctor agent D1, which has already been registered in the THOMAS platform, requests SearchService from SF to find services of interest (message 1). As a result, D1 obtains SearchPatientl service identifier and ranking value (message 2 ). Then, D1 employs GetProfile (message 3), which specifies that service doctor must play Doctor Role within HomeCare (message 4). Therefore, D1 must acquire Doctor Role to demand this service (messages 5 and $6)$.

Once D1 plays this Doctor Role, it employs GetProcess service in order to find out who the service providers are and how this service can be requested (message 7). However, there are no providers for the general SearchPatient service (message 8).

Within the HomeCare unit, D1 requests SearchService again (message 9). In this case, SF returns IdentifyPatient services because both services are accessible from HomeCare organization.

D1 demands the profile of IdentifyPatient service (using GetProfile, message 11), since this service is more appropriate for its needs. Taking the IdentifyPatient profile into account (message 12), D1 requests the adoption of LocationDoctor role within LocationUnit (message13).

\subsubsection{Service request}

This scenario shows how doctor agents make demands for services (Fig. 10). Once D1 adopts the Doctor Role for SearchPatient service, it is allowed to demand services from providers. Assuming that D1 wants to make an information search about patients, it should use GetProcess service to obtain the implementations of available services and also its provider identifiers (message 1).

An implementation of SearchPatient has been previously registered by $\mathrm{HC} 1$ and $\mathrm{HC} 2$. After comparing providers of SearchPatient service returned in message 2, D1 chooses to make a service request from $\mathrm{HC} 1$ agent (message 3). Both ACL contents for requesting and reporting messages are detailed in Table 7.

\subsubsection{Agent expulsion}

In this scenario, the expulsion of a malicious agent is carried out (Fig. 11). Provider agent detects that different doctor agents (D1

Table 7

Service profiles for the HomeCare system.

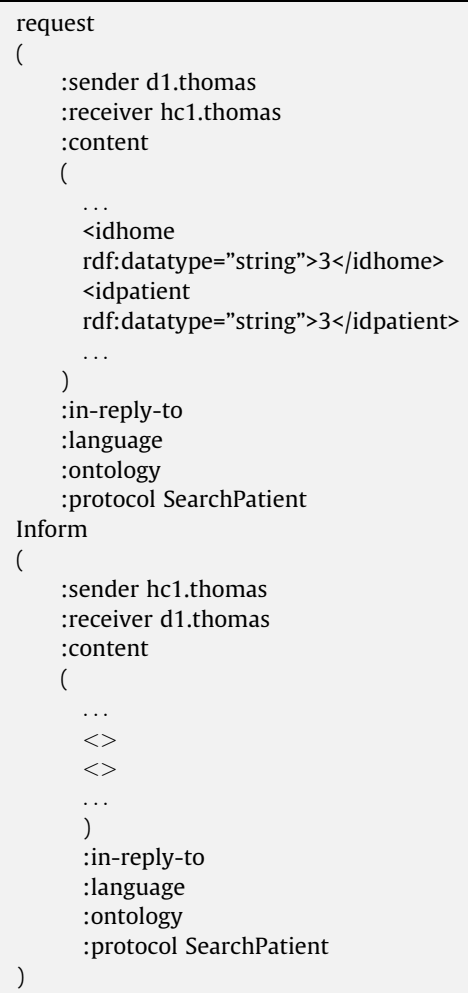

3. SearchPatient(3, 3)

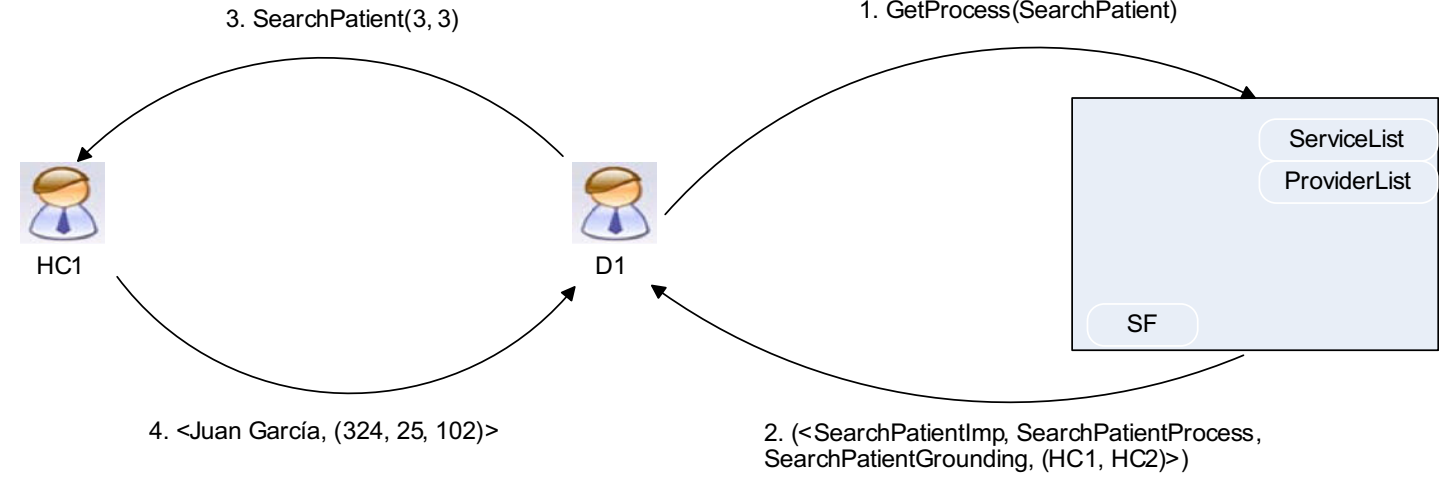

Fig. 10. Example of service request. 
1. Expulse (D2, HomeCare, Doctor)

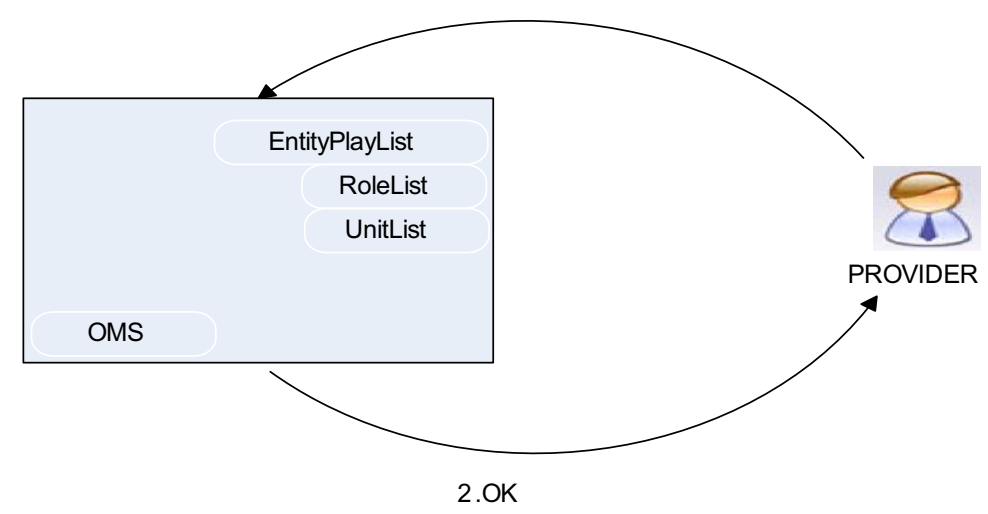

Fig. 11. Example of agent expulsion.

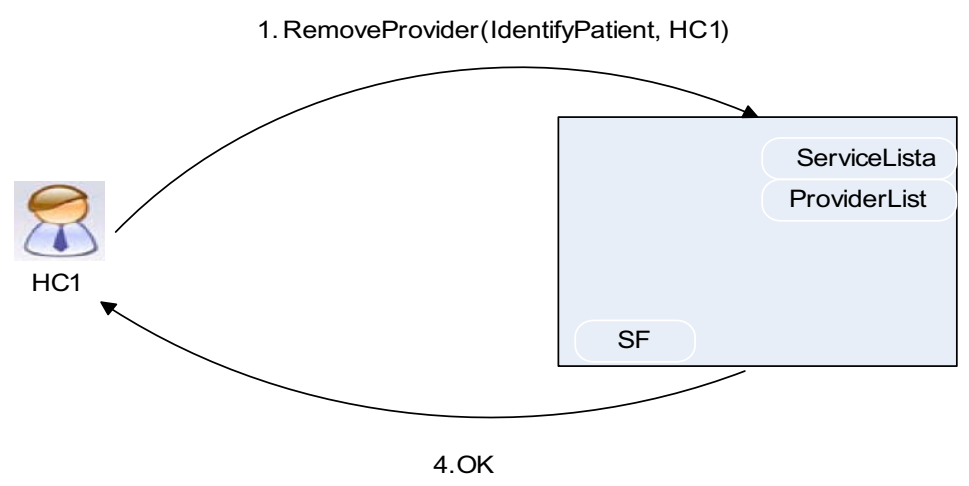

Fig. 12. Example of agent deregistration

1. RegisterUnit (LuxuryUnit, Provider, HomeCare)

3. RegisterRole (LuxuryProvider, LuxuryUnit, Public, External, Member)

4. RegisterRole (LuxuryPatient, LuxuryUnit, Public, External, Member)

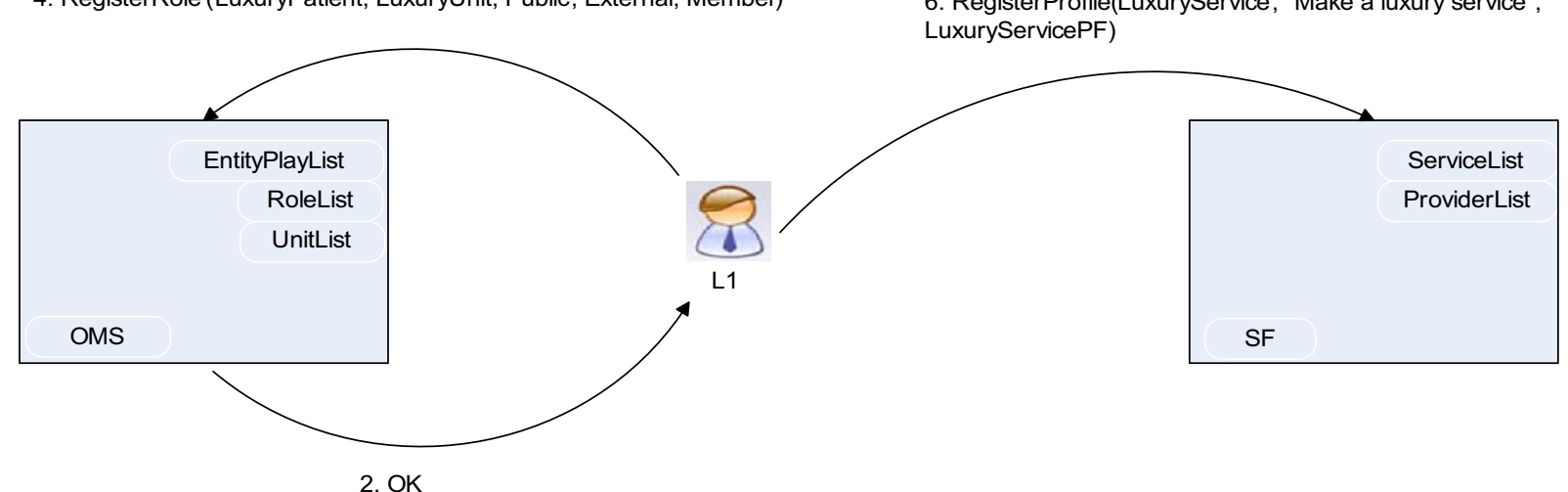

Fig. 13. Example of new unit creation.

and D2) have registered with the same identifier number. It consults its database and determines that D2 has been employing an identifier number that does not belong to it. D2 is punished for its fraudulent behaviour and is expelled from HomeCare. Provider requests the expulsion of D2 from OMS employing Expulse service (message 1).

\subsubsection{Provider deregistration}

Below, the process of a service provider deregistering is described (Fig. 12). HC1 loses connection with its internal database.
As a result, it is temporarily unable to provide services. Therefore HC1 deregisters itself as provider of IdentifyPatient using RemoveProvider (Fig. 12, messages 1 and 2).

$\mathrm{HC1}$ is deleted from the service provider list. Nevertheless, as it continues playing the Provider role, HC1 will be able to register itself as service provider if it recovers its functionality.

\subsubsection{Unit creation}

This last scenario illustrates the creation of new units within HomeCare (Fig. 13). Agent L1 represents a luxury Home Care 
Table 8

Final content of SF ServiceList after execution of all scenarios.

\begin{tabular}{lll}
\hline ServiceFacilitator & & \\
\hline ServiceID & Profile & Providers \\
\hline OpenCloseDoor & OpenCloseDoorPF & \\
SearchPatient & SearchPatientPF & SearchPatient(HC1, HC2) \\
IdentifyPatient & IdentifyPatientPF & \\
SearchLuxury & SearchLuxuryPF & \\
\hline
\end{tabular}

Table 9

Final content of OMS internal lists after execution of all scenarios.

\begin{tabular}{|c|c|c|c|c|}
\hline \multicolumn{5}{|l|}{ UnitList } \\
\hline UnitName & ParentUnit & Goal & & Type \\
\hline Virtual(world) & - & - & & Flat \\
\hline HomeCare & Virtual & HomeCare & & Congregation \\
\hline HCServiceUnit & HomeCare & HomeCareServ & & Flat \\
\hline LocationUnit & HomeCare & HomeCareLoca & tion & Flat \\
\hline AlertUnit & HomeCare & HomeCareAler & & Flat \\
\hline LuxuryUnit & HomeCare & HomeCareLux & & Flat \\
\hline \multicolumn{5}{|l|}{ RoleList } \\
\hline RoleName & inUnit & Accessibility & Position & Inheritance \\
\hline Patient & HomeCare & Public & Member & - \\
\hline Doctor & HomeCare & Public & Member & - \\
\hline Provider & HomeCare & Public & Member & - \\
\hline Family & HomeCare & Private & Member & - \\
\hline HCServicePatient & HCServideUnit & Public & Member & Patient \\
\hline HCServiceProvider & HCServideUnit & Public & Member & Provider \\
\hline HCServiceDoctor & HCServideUnit & Public & Member & Doctor \\
\hline LocationPatient & LocationUnit & Public & Member & Patient \\
\hline LocationProvider & LocationUnit & Public & Member & Provider \\
\hline LocationDoctor & LocationUnit & Public & Member & Doctor \\
\hline AlertPatient & AlertUnit & Public & Member & Patient \\
\hline AlertProvider & AlertUnit & Public & Member & Provider \\
\hline AlertDoctor & AlertUnit & Public & Member & Doctor \\
\hline LuxuryPatient & LuxuryUnit & Public & Member & Patient \\
\hline LuxuryProvider & LuxuryUnit & Public & Member & Provider \\
\hline LuxuryDoctor & LuxuryUnit & Public & Member & Doctor \\
\hline \multicolumn{5}{|l|}{ EntityPlayList } \\
\hline Entity & \multicolumn{2}{|l|}{ Unit } & \multicolumn{2}{|c|}{ Role } \\
\hline Doctor & \multicolumn{2}{|c|}{ HomeCare } & \multicolumn{2}{|c|}{ Doctor } \\
\hline $\mathrm{HC} 1$ & \multicolumn{2}{|c|}{ LocationUnit } & \multicolumn{2}{|r|}{ LocationPatient } \\
\hline $\mathrm{HC} 2$ & \multicolumn{2}{|c|}{ LocationUnit } & \multicolumn{2}{|r|}{ LocationPatient } \\
\hline D1 & \multicolumn{2}{|c|}{ LocationUnit } & \multicolumn{2}{|r|}{ LocationDoctor } \\
\hline D2 & \multicolumn{2}{|c|}{ HomeCare } & \multicolumn{2}{|r|}{ Doctor } \\
\hline L1 & \multicolumn{2}{|c|}{ LuxuryUnit } & \multicolumn{2}{|c|}{ LuxuryPatient } \\
\hline
\end{tabular}

company which specializes in luxury services. It is interested in providing information and very luxurious services. This L1 has already adopted the Provider role within HomeCare unit. However, since the services offered within LocationUnit and AlertUnit are specialized in location and alert domains, L1 decides to create a new unit (LuxuryUnit) within HomeCare (Fig. 13, message 1). This new unit will be focused on luxury Home Care. Once the OMS informs L1 about the successful creation of the new unit, L1 defines luxury-specific roles and services (messages 3 to 6). Finally, luxury agents would be able to adopt the LuxuryProvider role and start offering services to patient agents.

After all these scenarios, several agents have joined the THOMAS platform and offer or request services within this system. Table 8 shows the evolution of the ServiceList content, in which all of the new elements and relationships included as a result of the execution of these scenarios are emphasized. Similarly, OMS internal tables have also been updated (Table 9 ).

\section{Results and conclusions}

An important issue in the development of real open multiagent systems is to provide developers with methods, tools and appropriate architectures which support all of the requirements of these kinds of systems. This paper has studied this problem by proposing a case study on abstract architecture for the development of virtual organizations. Moreover, the proposal aims to instigate the total integration of two promising technologies, multi-agent systems and service-oriented computing, as the foundation of such virtual organizations. In THOMAS architecture, agents can transparently offer and invoke services from other agents, virtual organizations or entities; additionally, external entities can interact with agents through the use of the services offered.

A case study example was employed as an illustration of the usage of THOMAS components and services. Dynamic applications are also developed with the same architecture. In this way, examples of THOMAS service calls have been shown through several scenarios, along with the evolution of different dynamic virtual organizations. The participative approach presented in this work is also applicable to other knowledge production tasks as software development, especially in analysis and design phases. Nevertheless, further validation is needed to assess the usefulness of the architecture in different scenarios. We are also conducting tests on the impact of the number of agents in the overall effectiveness of the model. However, interaction processes are not completely independent from one another. Therefore, the participation of agents in the system can be dynamic, so that an agent can change its membership to some other system if the knowledge produced by the agent affects interaction processes carried out in that system.

\section{Acknowledgements}

This work was supported by the Spanish Ministry of Science and Technology project TIN2006-14630-C03-03 and the JCyL SA071A08 Project.

\section{References}

Anastasopoulos, M., Niebuhr, D., Bartelt, C., Koch, J., \& Rausch, A. (2005). Towards a reference middleware architecture for ambient intelligence systems. In ACM conference on object-oriented programming, systems, languages, and applications.

Angulo, C., \& Tellez, R. (2004). Distributed intelligence for smart home appliances. In Tendencias de la minería de datos en España (pp. 1-12). Barcelona: Red Española de Minería de Datos.

Argente, E., Palanca, J., Aranda, G., Julian, V., Botti, V., García-Fornes, A., et al. (2007) (pp. 236-245). Lecture notes in artificial intelligence (Vol. 4696). Berlin: Springer.

Augusto, J. C., \& McCullagh, P. (2007). Ambient intelligence: Concepts and applications. International Journal on Computer Science and Information Systems, 4(1), 1-28.

Bahadori, S., Cesta, A., Grisetti, G., Iocchi, L., Leone, R., Nardi, D., et al. (2003) RoboCare: Pervasive intelligence for the domestic care of the elderly. Artificial Intelligence, 1(1), 16-21.

Brogi, A., Corfini, S., \& Popescu, R. (2005). Composition-oriented service discovery. In Lecture notes in computer sciences (pp. 15-30). Berlin: Springer.

Camarinha-Matos, L., \& Afsarmanesh, H. (2004). TeleCARE: Collaborative virtual elderly care support communities. The Journal on Information Technology in Healthcare, 2(2), 73-86.

Carrascosa, C., Bajo, J., Julian, V., Corchado, J. M., \& Botti, V. (2008). Hybrid multiagent architecture as a real-time problem-solving model. Expert Systems With Applications, 34(1), 2-17.

Cesta, A., Bahadori, S., Cortellesa, G., Grisetti, G., \& Giuliani, M. (2003). The RoboCare project, cognitive systems for the care of the elderly. In Proceedings of international conference on aging, disability and independence (ICADI'03). Washington, DC, USA.

Costa-Font, J., \& Patxot, C. (2005). The design of the long-term care system in Spain Policy and financial constraints. Social Policy and Society, 4(1), 11-20.

Corchado, J. M., \& Laza, R. (2003). Constructing deliberative agents with case-based reasoning technology. International Journal of Intelligent Systems, 18 $1227-1241$. 
Corchado, J. M., Bajo, J., de Paz, Y., \& Tapia, D. (2008). Intelligent environment for monitoring alzheimer patients, agent technology for health care. Decision Support Systems, 34(2), 382-396.

Decker, K., \& Li, J. (1998). Coordinated hospital patient scheduling. In Proceedings of the 3rd international conference on multi-agent systems (ICMAS'98) (pp. 104-111). IEEE Computer Society.

Klusch, M., Fries, B., \& Sycara, K. (2006). Automated semantic web service discovery with owls-mx. In Proceedings of 5th international conference on autonomous agents and multi-agent systems (pp. 915-922). Hakodate, Japan.

Lanzola, G., Gatti, L., Falasconi, S., \& Stefanelli, M. (1999). A framework for building cooperative software agents in medical applications. Artificial Intelligence in Medicine, 16(3), 223-249.

Meunier, J. A. (1999). A virtual machine for a functional mobile agent architecture supporting distributed medical information. In Proceedings of the 12th IEEE symposium on computer-based medical systems (pp. 177). Washington, DC: IEEE Computer Society.
Miksch, S., Cheng, K., \& Hayes-Roth, B. (1997). An intelligent assistant for patient health care. In Proceedings of the 1st international conference on autonomous agents, California, USA (pp. 458-465). New York: ACM.

Nealon, J. L., \& Moreno, A. (2003). Applications of software agent technology in the health care domain. In A. Moreno \& J. L. Nealon (Eds.). Whitestein series in Software Agent Technologies (Vol. 212). Basel, Germany: Birkhäuser Verlag AG.

Pecora, F., \& Cesta, A. (2007). Dcop for smart homes: A case study. Computational Intelligence, 23(4), 395-419.

Sycara, K., Widoffand, S., Klusch, M., \& Lu, J. (1982). Larks: Dynamic matchmaking among heterogeneous software agents in cyberspace. Journal on Autonomous Agents and Multi-Agent Systems, 5, 173-203.

Van Woerden, K. (2006). Mainstream developments in ICT: Why are they important for assistive technology? Technology and Disability, 18(1), 15-18.

Want, R., Pering, T., Borriello, G., \& Farkas, K. (2002). Disappearing hardware. Pervasive Computing, 1(1). 